\title{
SOBRE O ENSINO DA ARTE: SUGESTÃO
}

Eliane Patricia Grandini Serrano ${ }^{1}$

Nelyse Ap. Melro Salzedas ${ }^{2}$

\section{Resumo}

Este texto considera a obra de arte como um texto, que para ser lido faz-se necessário percorrer o caminho: olhar, ver e compreender, sendo que cada etapa constitue momentos de aprendizagem e de prazer estético, um verdadeiro processo de letramento visual.

Ensinar a ler a linguagem artística, a vê-la através do rítmo e do movimento como produção de sentido e de estesia. Eis a nossa proposta.

Palavras-chave: Leitura, olhar, ver.

\begin{abstract}
This study considers the master-piece as a text, which is necessary to go through a course to be read: to look, see and understand. Which stage of reading is composed of learning moments and aesthetic pleasure a true visual learning process.

Our porpose is to teach the art language, to look trought the rhythm and moviment as a aesthetical and meaning production.
\end{abstract}

Key-words: reading; to look, see.

A nossa primeira afirmação: a arte é linguagem. É uma afirmação genérica que figura na Poética de Aristóteles.

Após essa assertiva, segue-se uma interrogação, em que elas se diferem? Ainda, segundo Aristóteles, nos meios: uma usa a música; outra, a narrativa; outra, o desenho; outra, a dança. E nos dias de hoje, a multimídia. Propomos discutir o assunto sobre o ensino da arte através de algumas considerações, a partir de vários textos como: A Poética de Aristóteles, O Sexto Sentido de Rubem Alves; Natalika de G. de Almeida e a Fábula A Cigarra e a Formiga, de M. Lobato, pode-se perceber que todos podem ser considerados textos onde a arte está inserida através de seus sígnos específicos .

Em um fragmento do texto de R. Alves, temos uma amostragem de um como e um porquê olhar de forma diferenciada:

Fugir, brincar de faz-de-conta, tratar as coisas que são como se não fossem - é dessa loucura que surgem as mais belas criações da Arte e da Ciência. Me daria por feliz se a educação introduzisse os alunos no mundo mágico do pensamento, assim como acontece na literatura. Quem experimentou a magia do pensamento uma única vez na vida não se esquece jamais (Sexto sentido - extraído em 26/07/2005 do Jornal O Estado de São Paulo).

Ensinar a ler a linguagem da Arte, mais especificamente a arte pictórica, a vê-la e a ouví-la através do rítmo e do momento como produção de sentido e de estesia, eis a nossa proposta.

A história da arte interessa-se na maioria das vezes pelas telas. Ela se contenta, pode-se dizer, pelas descrições curtas e sumárias que acaba redundando em considerações

1 UNESP - Presidente Prudente.

2 UNESP - Assis/Bauru. 
gerais, biográficas, sociológicas e históricas. Tudo se passa como se as obras existiam para ilustrar s estilos ainda que, longe de ser um suporte deles, eles seriam as suas forças vivas.

Essa tendência conduz para criar grandes conjuntos que, de escola à escola, de época à época, sucedeu-se, combateu-se e trocam de posição. Uma tal relação é certamente legítima e até louvável, mas uma outra é possível, que consiste em privilegiar a leitura dos quadros enquanto preâmbulo a toda relação global da arte.

Enquanto passeia-se pela longa galeria dos museus, vai se parando, vai-se transitando sobre nossos passos, indo e voltando e aí encontra-se, com efeito, diante das obras e não diante de teorias. É assim no Louvre, com La Gioconda de Da Vinci ; na National Galery de Londres com Embaixadores de Holbein; no Museu do Prado com o Fuq̨ilamento de Três de Maio de Goya e no Orsay com Almoço sobre a Relva de Manet.

Após essas visitas ao Louvre, Narional Galery, Prado e Orsay, descobre-se que não se pode ver tudo, seria necessário meses e anos para fazê-lo. Entretanto há nesses museus quadros que atraem o nosso olhar, é frente a ele que se pára. Por quê?

A causa está na fenomenologia do olhar segundo Alfredo Bosi e Gandelman. Bosi dirige seu ensaio sobre esse assunto enfocando o olhar e o ver; Gandelman, ao estudar o toque do olho, recorta-o através do olho tátil e do olho ótico.

Eis como esses dois teóricos se posicionam; pela diferenciação entre o olho e olhar. Se em português os dois aparentemente se casam, em outras línguas a distinção é clara: em espanhol "ojo" é órgão mas o ato de olhar é "mirada"; em francês "oeil" é olho mas o ato é "regard"; em inglês "eye" não está em "look"; em italiano olho é "occhio" e olhar e "sguardo". O que esclarece a diferenciação entre a função de um órgão e o ato desse órgão que trata do ato perceptivo. Bosi ainda retoma vertentes do pensamento antigo sobre olhar/conhecer enfocando suas dimensões: o olhar receptivo e ativo. Estuda igualmente o novo olhar chamado perspectiva, que é renascentista e por fim o olhar como expressão.

A cultura grega, acentuadamente plástica, enlaçava pelos fios da linguagem o ver ao pensar. Eidos, forma ou figura, é termo afim de a idea. Em latim, com pouca diferença de sons: vídeo (eu vejo) e idea. E os etimologistas encontram na palavra história (grega e latina) o mesmo étimo id, que está em eidos e em Idea. (BOSI,A. 1988)

Esse texto foi retomado e discutido no Projeto de Educação Continuada durante os anos de 1996/1998, dirigido pelo Núcleo de Ensino da UNESP - Campus de Bauru; que termina com a frase "Aprenda a olhar".

A partir daí o caderno produzido por esse núcleo de ensino passa a discutir o olhar e o ver na obra de arte, trabalhando com textos de Alberto Manguel: O leitor simbólico e com o texto de Leila Perrone Moiséis: Pensaré estar doente dos olhos.

Retomando os heterônimos de Fernando Pessoa, a ensaista aponta o olhar como responsável pela descoberta e representação do mundo, ao citar versos de cada um dos múltiplos do poeta português. Vejamos alguns que direcionam a representação do mundo:

Contemplo o que não vejo (F.P. - O.C. p.170)

O meu olhar é nitido como um girassol (A. C. - O. C. p. 24)

Pensar uma flor é vê-la, cheirá-la

E comer um fruto é saber-lhe o sentido (A. C. - O. C. p. 212)

O mundo exterior claramente vejo-

Coisas, homens sem alma (R. C. - O. C. p. 287)

Ah, olhar é em mim uma perversão sexual (A. Campos - O. C. p. 309) 
Todos esses olhares levam-nos a uma conclusão: não se olha sempre da mesma maneira, o mundo é uno, mas os olhares sobre ele são diferentes e as representações, também, logo ensinar a ler a obra de arte é ensinar a olhar a ver. Para depois ter o prazer estético. O texto de Manguel, discutido no caderno, fecha-se com a recomendação "Aprenda a Ler".

Essa proposta de ensino da leitura da obra de arte baseia-se fundamentalmente no ato de ver, isto é, na leitura, sempre pensando na tela, como um texto.

Gandelman tem o mesmo ponto de partida, ao nomear o seu livro com Le Regard dans le texte. O primeiro capítulo é fundamental para os outros que se seguem pois é na conceituação de olho e de olhar que o referido autor desenvolve todo o seu livro.

Em Le toucher de l'oeil, retoma como Bosi o conceito de olho, embora trate o processo argumentativo diferentemente, ao classificar o olho tátil e ótico. Ao focalizar o olho tátil mergulha na civilização egípcia e chega ao realismo de Courbet. O primeiro a ser tratado é a escrita hieróglifa, cujo olho simbolicamente nomeia o criador, aquele que fez o céu e a terra. Dessa maneira o realizador comporta sempre perto de si o verbo fazer, o olho é assim um símbolo por excelência do performativo. O outro olho "wadjat-eye", o olho wadjat está sempre à esquerda de Horus. É muitas vezes por meio de uma mão que tal que esse desenho aparece sobre o arco da tumba de Pashedu

Entretanto, o olho toma o sentido daquele que toca o objeto e esse ato remete o texto a Courbet: é este hieróglifo do olho que toca as coisas que o autor vê na pintura do Auto retrato de Courbet no meio de seu ateliê. Assim sendo, olho e mão casam-se: o olhar e o fazer.

Em outro tópico Gandelman retoma o assunto voltando seu enfoque para o "optique" e "haptique" que são duas categorias fundamentais de d'Alois Riegel que serão mais tarde retomadas por Wolfflin ao dicotomizar o linear pictórico. O olho tátil penetra na profundidade, o "haptique" se dirige ao volume e às texturas.

Essas considerações foram feitas refletindo como ensinar a ler uma obra de arte sempre pensando na tela como um texto cujos fios que o tecem, que o desenham são produtores de sentido, assim, várias correntes teóricas propõem leituras diferenciadas como: o historicismo, a sociologia, a psicologia, o estruturalismo, a fenomenologia e a estética de recepção cujo enfoque reside no texto e seu efeito no leitor.

Considerando a afirmação do crítico francês Gerard Genette, todos os elementos que cercam o texto tem como finalidade produzir o ato da leitura, entendemos aqui leitura o ato de colher, ligar, produzir sentidos, cujo étimo latino "legêre" sugere. Para que isso aconteça, faz-se necessário percorrer o caminho: olhar, ver e compreender, sendo que cada etapa constitue momentos de aprendizagem e de prazer estético, um verdadeiro processo de letramento visual.

O texto determina a forma de lê-lo, lembrando sempre com Jean Ferrier que ele não é um pretexto para se estudar o estilo, a estética, a história e a escola a qual pertence, antes ele é o determinante da escola, da época, da história.

O leitor de uma obra de arte entra no processo do letramento para desenvolver as habilidades da leitura e criar a competência para realizá-la. A função docente é criar esse leitor e torná-lo apto para ver/conhecer/fruir a obra de arte.

\section{Referências bibliográficas}

BOSI, A., A Fenomenologia do olhar. In NOVAES, M. O olhar, SP:Schwarez, 1990.

FERRIER, Jean-Louis. Les Aventures du regard. Paris: Edition Jean Claude Lattés,1996. 
GANDELMAN, C. Le regard dans le texte. Paris: Meridiens Klinckssieck,1986.

MANGUEL, A. A história da leitura. SP: Companhia da Letras, 1997 